\title{
Validity of heart-rate based measurements of oxygen consumption during work with light and moderate physical activity
}

\author{
Eva Bernmark $^{\mathrm{a}^{*}}$, Mikael Forsman ${ }^{\mathrm{a}}$, Gunilla Pernold ${ }^{\mathrm{a}}$ and Christina Wiktorin ${ }^{\mathrm{a}}$ \\ ${ }^{a}$ Division of Occupational and Environmental Medicine, Department of Public Health Sciences, Karolinska Insti- \\ tutet, SE-171 76 Solna, Sweden.
}

\begin{abstract}
For ergonomic purposes it is useful to quantify the energy expenditure and the level of physical activity imposed on workers. Oxygen consumption $\left(\mathrm{VO}_{2}\right)$ is often used to calculate energy expenditure and can be used as an indication of physical activity. Twenty-five subjects participated in the study. Oxygen consumption $\left(\mathrm{VO}_{2}\right)$ in $\mathrm{L} \mathrm{O}_{2} /$ min and heart-rate (HR) in beats per minute (bpm) were simultaneously measured during different work tasks at each individual's workplace. Ninety-one different work tasks with light or moderate physical activity were included (physical activity was classified by the $\mathrm{VO}_{2}$ measurements). Estimated oxygen consumption $\left(\mathrm{L} \mathrm{O}_{2} / \mathrm{min}\right.$ ) was then calculated by using the HR measurements in bpm combined with individual $\mathrm{HR}-\mathrm{VO}_{2}$ equations established in a laboratory. Although heart-rate based estimations of individual oxygen consumption showed relatively low precision, heart-rate measurements in combination with individual exponential $\mathrm{HR}^{-\mathrm{VO}_{2}}$ equations can be used to discriminate between work involving light physical activity and work involving moderate physical activity.
\end{abstract}

Keywords: energy expenditure, work load, exposure assessment, heart rate, oxygen consumption

\section{Introduction}

For ergonomic purposes it is useful to quantify the energy expenditure and the level of physical activity imposed on workers. Oxygen consumption $\left(\mathrm{VO}_{2}\right)$ is often used to calculate energy expenditure and can be used as an indication of physical activity. Work involving heavy physical activity is often combined with use of high muscle forces. This can lead to musculoskeletal disorders $[2-4,6]$. In physically strenuous work with heavy physical activity, periods of recovery are important to prevent the total physical load during a working day from exceeding an individual's threshold levels $[1,5,7]$.

The present study addressed two research questions: 1) Can heart-rate based measurements be used to discriminate between work involving light physical activity and work involving moderate physical activity? And 2) what is the precision of heart-rate based estimations of oxygen consumption in work with light or moderate physical activity?

\section{Methods}

Twenty-five subjects participated in the study. Oxygen consumption $\left(\mathrm{VO}_{2}\right)$ in $\mathrm{L} \mathrm{O}_{2} / \mathrm{min}$ and heartrate (HR) in beats per minute (bpm) were simultaneously measured during different work tasks at each individual's workplace. Ninety-one different work tasks with light or moderate physical activity were included (physical activity was classified by the $\mathrm{VO}_{2}$ measurements). Estimated oxygen consumption $\left(\mathrm{VO}_{2 \mathrm{EST}}\right)\left(\mathrm{L} \mathrm{O}_{2} / \mathrm{min}\right)$ was then calculated by using the $\mathrm{HR}$ measurements in bpm combined with individual $\mathrm{HR}-\mathrm{VO}_{2}$ equations established in a laboratory.

\section{Results}

Direct HR measurements in bpm to estimate the level of physical activity correctly classified 60 of the 91 work tasks. The alternative $\mathrm{VO}_{2 \mathrm{EST}}$-method correctly classified estimated level of physical activity

*Corresponding author. E-mail: mikael.forsman@ki.se 
for 82 of 91 work tasks. The mean difference between $\mathrm{VO}_{2}$ and $\mathrm{VO}_{2 \mathrm{EST}}$ for work tasks with light or moderate physical activity was $0.05(95 \% \mathrm{CI} ; 0.02-$
$0.08) \mathrm{L} \mathrm{O}_{2} / \mathrm{min}$ and the $\pm 95 \%$ limits of agreement was $\pm 0.27 \mathrm{~L} \mathrm{O}_{2} / \mathrm{min}$ (figure 1).

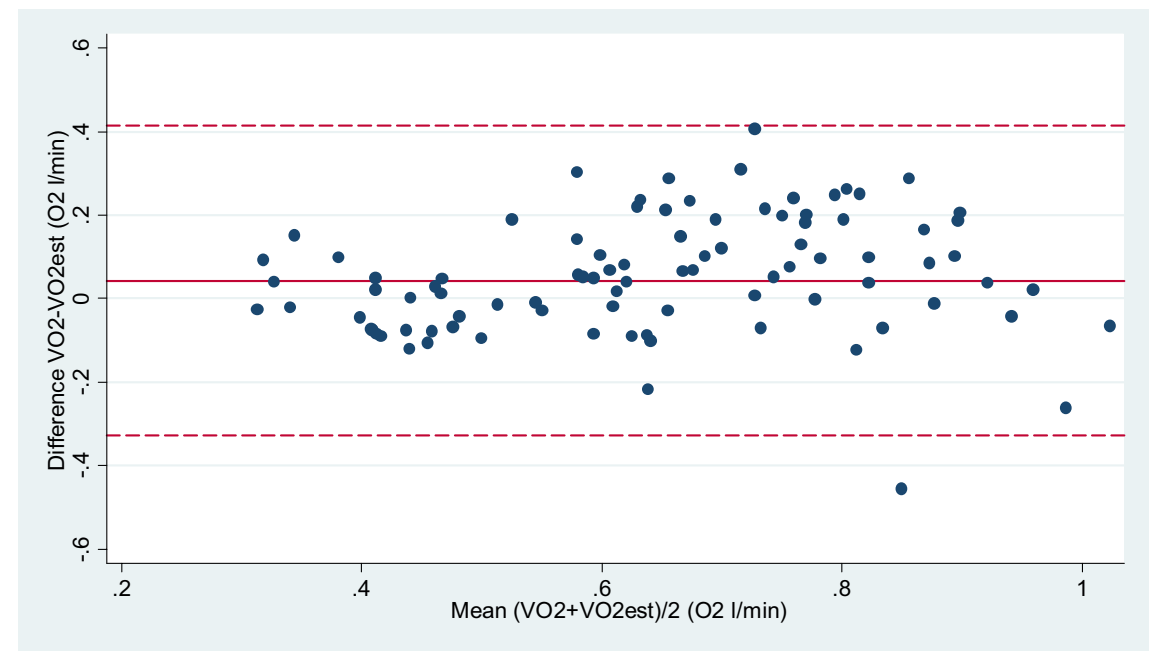

Figure. 1. Work tasks with light or moderate physical activity. Bland-Altman plot of the differences between measured oxygen consumption $\left(\mathrm{VO}_{2}\right)$ and the estimated oxygen consumption from the heart-rate measurements $\left(\mathrm{VO}_{2 \mathrm{EST}}\right)\left(\mathrm{L} \mathrm{O}_{2} / \mathrm{min}\right)$. The solid line represents the mean difference. Dashed lines represent upper and lower limits of agreement, calculated as the mean differences $\pm 1.96 \mathrm{SD}\left(\mathrm{L} \mathrm{O}_{2} / \mathrm{min}\right)$. Number of work tasks $(\mathrm{n}=91)$.

\section{Discussion}

Although heart-rate based estimations of individual oxygen consumption showed relatively low precision, heart-rate measurements in combination with individual exponential $\mathrm{HR}-\mathrm{VO}_{2}$ equations can be used to discriminate between work involving light physical activity and work involving moderate physical activity.

\section{References}

[1] P.O. Astrand, K. Rodahl, H. Dahl, S. Stromme. Textbook of Work Physiology: Physiological Bases of Excercise. 4 th ed: Human Kinetics; 2003.

[2] S. Gangopadhyay, T. Ghosh, T. Das, G. Ghoshal, B.B. Das, Prevalence of upper limb musculo skeletal disorders among brass metal workers in West Bengal, India. Ind Health 45 (2007), $365-70$

[3] E.F. Harkness, G.J. Macfarlane, E.S. Nahit, A.J. Silman, J. McBeth, Mechanical and psychosocial factors predict new onset shoulder pain: a prospective cohort study of newly employed workers. Occup Environ Med 60 (2003), 850-7.

[4] W.E. Hoogendoorn, P.M. Bongers, H.C. de Vet, G.A Ariens, W. van Mechelen, L.M. Bouter, High physical work load and low job satisfaction increase the risk of sickness absence due to low back pain: results of a prospective cohort study. Occup Environ Med 59 (2002), 323-8.

[5] K. Jorgensen, Permissible loads based on energy expenditure measurements. Ergonomics 28 (1985), 365-9.

[6] H. Miranda, L. Punnett, E. Viikari-Juntura, M. Heliovaara, P. Knekt, Physical work and chronic shoulder disorder. Results of a prospective population-based study. Ann Rheum Dis 67 (2008), 218-23

[7] H.C. Wu, M.J. Wang, Relationship between maximum acceptable work time and physical workload. Ergonomics 45 (2002), 280-9. 